\title{
Caracterização epidemiológica e fatores de risco associados à infecção por Brucella ovis em ovinos deslanados do semiárido paraibano ${ }^{1}$
}

\author{
Fabrine A. Santos ${ }^{2}$, Severino S.S. Higino², Sergio S. Azevedo², Diego F. Costa ${ }^{2}$, \\ Areano E.M. Farias ${ }^{2}$, Francisco A.L. Alves ${ }^{2}$, Lilia M. Paulin ${ }^{3}$ e Clebert J. Alves ${ }^{2 *}$
}

\begin{abstract}
Santos F.A., Higino S.S.S., Azevedo S.S., Costa D.F., Farias A.E.M., Alves F.A.L., Paulin L.M. \& Alves C.J. 2013. [Epidemiological characterization and risk factors associated with Brucella ovis infection in sheep in the Brazilian semiarid.] Caracterização epidemiológica e fatores de risco associados à infecção por Brucella ovis em ovinos deslanados do semiárido paraibano. Pesquisa Veterinária Brasileira 33(4):459-463. Unidade Acadêmica de Medicina Veterinária, Centro de Saúde e Tecnologia Rural, Universidade Federal de Campina Grande, Av. Universitária s/nº, Patos, PB 58700-970, Brazil. E-mail: clebertja@uol.com.br

The aim of this investigation was to determine the seroprevalence of Brucella ovis in sheep flocks and individual sheep in the Sertão mesorregion, Paraíba state, Northeastern Brazil, as well as to identify risk factors. Blood samples were collected from 1,134 sheep from 103 flocks in 17 counties. For the serological diagnosis of $B$. ovis infection the agar gel immunodiffusion test (AGID) was carried out. A flock was considered positive when there was at least one seropositive animal. Of the 103 flocks used, 21 (20.39\%) presented at least one seropositive sheep, and of the 1,134 sheep examined 59 (5.20\%) seropositive animals were diagnosed. Cleaning of facilities (odds ratio $=7.13 ; 95 \% \mathrm{CI}=1.56-32.47 ; \mathrm{p}=0.011$ ) and purchase of animals (odds ratio $=6.06$; $95 \% \mathrm{CI}=1.39-26.48$; $\mathrm{p}=0.017$ ) were identified as risk factors. Based on the risk factor analysis, it is recommended the diagnosis of $B$. ovis infection prior to purchase of sheep and the periodic cleaning of the facilities on the farm.
\end{abstract}

INDEXING TERMS: Brucellosis, Brucella ovis, sheep, epidemiology, Semiarid of Brazil.

\begin{abstract}
RESUMO.- Este trabalho teve como objetivo determinar a prevalência de rebanhos ovinos positivos (focos) e de animais soropositivos para Brucella ovis na mesorregião do Sertão, Estado da Paraíba, Nordeste do Brasil, bem como identificar fatores de risco. Foram colhidas amostras de sangue de 1.134 animais procedentes de 103 rebanhos em 17 municípios. Para o diagnóstico sorológico da infecção por $B$. ovis foi utilizado o teste de imunodifusão em gel de ágar (IDGA). Um rebanho foi considerado positivo quando apresentou pelo menos um animal soropositivo. Das 103 propriedades utilizadas 21 (20,39\%) apresentaram pelo

\footnotetext{
${ }^{1}$ Recebido em 20 de novembro de 2012.

Aceito para publicação em 11 de março de 2013.

${ }^{2}$ Unidade Acadêmica de Medicina Veterinária, Centro de Saúde e Tecnologia Rural, Universidade Federal de Campina Grande (UFCG), Av. Universitária s/n, Patos, PB 58700-970, Brasil. *Autor para correspondência: clebertja@uol.com.br

${ }^{3}$ Centro de Desenvolvimento e Pesquisa de Sanidade Animal, Instituto Biológico, Rua Conselheiro Rodrigues Alves 1252, São Paulo, SP 04014002, Brasil.
}

menos um animal soropositivo e dos 1.134 animais, 59 $(5,20 \%)$ foram soropositivos. Realizar higiene nas instalações com periodicidade anual (odds ratio $=7,13$; IC $95 \%$ $=1,56-32,47 ; \mathrm{p}=0,011$ ) e aquisição de animais (odds ratio = 6,06; IC 95\% = 1,39-26,48; $\mathrm{p}=0,017$ ) foram identificados como fatores de risco. Com base na análise de fatores de risco, recomenda-se a realização de diagnóstico da infecção por B. ovis previamente à aquisição de animais e realização periódica de higienização das instalações.

TERMOS DE INDEXAÇÃO: Brucelose, Brucella ovis, ovinos, epidemiologia, semiárido do Brasil.

\section{INTRODUÇÃO}

A ovinocultura brasileira destaca-se no cenário nacional por apresentar grande potencial de crescimento, tendo-se observado, nos últimos anos, uma evolução significativa no rebanho nacional, contando hoje com efetivo de ovinos que chega a mais de 16 milhões de cabeças (IBGE 2006). Este crescimento pode ser explicado pelas inúmeras vantagens 
que apresentam como a necessidade de menor área de criação, menor consumo de alimentos, facilidade de manejo e grande diversidade de produção de carne e couro de boa qualidade, servindo como alternativa de renda. Contudo, deficiências sanitárias envolvidas no processo evolutivo da ovinocultura brasileira, tais como os prejuízos provocados pelas perdas associadas à necessidade de reposição dos animais em decorrência de doenças infecciosas, necessitam de correção (Fernandes 2009).

Entre as doenças com impacto na esfera reprodutiva, a brucelose ovina por Brucella ovis deve ser considerada uma das possíveis causas de abortamentos, sendo uma das principais causas de perdas econômicas no rebanho. A infecção foi descrita inicialmente na Nova Zelândia (Buddle \& Boyes 1953) e na Austrália (Simmons \& Hall 1953), e posteriormente evidenciada na grande maioria dos países onde a ovinocultura tem importância econômica (Estein 1999). No Brasil, a doença foi descrita pela primeira vez em 1996 no Rio Grande do Sul (Ramos et al. 1966), que detectaram epididimite clínica em 6,5\% dos 3.317 carneiros estudados. Em seguida, trabalhos de investigação sorológica foram publicados, mostrando que a infecção está difundida em vários estados do país, com prevalência variando de 5 a 35\% (Boblel et al. 1972, Magalhães-Neto \& Gil-Turnes 1996, Azevedo et al. 1999, 2004, Coleto et al. 2003, Medeiros 2003, Silva et al. 2003, Nozaki et al. 2004, Clementino et al. 2007).

A brucelose ovina é caracterizada por um processo infeccioso clínico ou subclínico e de tendência à cronicidade, com lesões genitais de epididimite no macho e placentite nas fêmeas com alguns casos de abortamento, levando a mortalidade de recém-nascidos e elevada frequência de nascidos com baixo peso e baixa viabilidade condicionando à elevada mortalidade em cordeiros (Niilo et al. 1986, Homse et al. 1995, Baigun et al. 2000). As lesões produzidas pela $B$. ovis no aparelho reprodutor masculino incluem epidídimo aumentado de volume e endurecido, túnicas escrotais engrossadas e testículos geralmente atrofiados (Schäfer et al. 1997).

0 diagnóstico da infecção por B. ovis tem sido feito, predominantemente, através de testes sorológicos, sendo que alguns autores recomendam que o histórico do rebanho e o quadro clínico também sejam levados em consideração ao se interpretar o resultado dos testes sorológicos (Marinho \& Mathias 1996). Dentre as várias provas utilizadas no diagnóstico de brucelose ovina, destacam-se a fixação de complemento, o teste de imunodifusão em ágar gel e o teste de ELISA indireto (Hilbink et al. 1993, West et al. 1993, Kumar et al. 1997). Worthington et al. (1984), investigando ovinos na Nova Zelândia em condições experimentais, demonstraram, para as provas de fixação de complemento, ELISA indireto e imunodifusão em ágar gel, sensibilidades de $96,3 \%, 97,2 \%$ e $91,7 \%$, e especificidades de $99,3 \%$, $98,6 \%$ e $100 \%$, respectivamente.

Tendo em vista que a infecção por B. ovis já foi identificada em diversos estados brasileiros e que a infecção está contemplada no Programa Nacional de Sanidade de Caprinos e Ovinos (PNSCO) do Ministério da Agricultura, Pecuária e Abastecimento (Brasil 2004) e considerando a hipó- tese de que a infecção por B. ovis está presente nos estados nordestinos, inclusive na Paraíba, estruturou-se o presente trabalho com o objetivo de determinar a prevalência de propriedades positivas (focos) e de animais positivos, bem como identificar os fatores de risco em ovinos deslanados do semiárido da Paraíba.

\section{MATERIAL E MÉTODOS}

O Estado da Paraíba é dividido geograficamente em quatro mesorregiões (Sertão Paraibano, Borborema, Agreste Paraibano e Mata Paraibana) e 23 microrregiões. A mesorregião do Sertão Paraibano possui como principal atividade a pecuária extensiva, assumindo destaque a criação de ovinos. No presente trabalho foram utilizados ovinos deslanados adultos provenientes da mesorregião do Sertão.

A amostragem foi delineada para a determinação da prevalência de propriedades positivas e de animais soropositivos, de maneira que foi conduzida em dois estágios. Inicialmente, as propriedades foram aleatoriamente selecionadas. 0 número de propriedades a serem amostradas foi calculado com o programa Epiinfo versão 6.04 (Dean 1994), com o emprego dos seguintes parâmetros: prevalência esperada de $50 \%$ (valor adotado para maximizar a amostra), nível de confiança de $95 \%$ e erro absoluto de 10\% (Thrusfield 1995). Na mesorregião do Sertão o total de propriedades criadoras de ovinos é de 7.087, resultando em uma amostra de 96 propriedades. Por motivo de segurança foram visitadas 103 propriedades.

O número de ovinos a serem selecionados foi determinado individualmente por propriedade com o objetivo de detectar a presença da infecção, utilizando a seguinte fórmula (Thrusfield 1995):

$$
\begin{aligned}
& \mathrm{n}=\left[1-(1-\mathrm{p})^{1}\right] \mathrm{x}\left(\mathrm{N}-\frac{\mathrm{d}}{2}\right)+1 \\
& \text { onde: } \\
& n=\text { tamanho da amostra; } \\
& p=\text { probabilidade de detectar pelo menos um animal soropositivo; } \\
& N=\text { tamanho do rebanho; } \\
& d=\text { número de animais soropositivos no rebanho. }
\end{aligned}
$$

A probabilidade de detecção de pelo menos um animal soropositivo foi de $95 \%(\mathrm{p}=0,95)$, e o número de animais soropositivos por rebanho (d) foi calculado assumindo prevalência intra-rebanho de 5\% (Clementino et al. 2007).

No total foram utilizados 1.134 animais procedentes de 103 propriedades de 17 municípios da mesorregião do Sertão paraibano (Fig.1). 0 trabalho de campo foi desenvolvido no período de julho de 2010 a julho de 2011. As amostras de sangue foram colhidas de ovinos deslanados adultos pela punção da veia jugular com agulha descartável e tubo a vácuo. Após o dessoramento, os soro foram transferidos para microtubos e congelados até a realização da prova sorológica.

Foi aplicado um questionário epidemiológico para obtenção de informações sobre problemas reprodutivos, comercialização de animais, participação em exposições, sistema de criação e manejo dos animais, principal atividade da propriedade e contato com outros animais. Os dados obtidos com os questionários foram utilizados no estudo de fatores de risco.

A imunodifusão em gel de agar (IDGA) foi a técnica utilizada como prova diagnóstica e realizada no Laboratório de Doenças Transmissíveis/CSTR/UFCG. Foram utilizados kits produzidos pelo Instituto de Tecnologia do Paraná (TECPAR), sendo a técnica realizada de acordo com as instruções do fabricante utilizando-se antígeno de lipopolissacarídeos e proteínas de B. ovis, amostra Reo 198. 


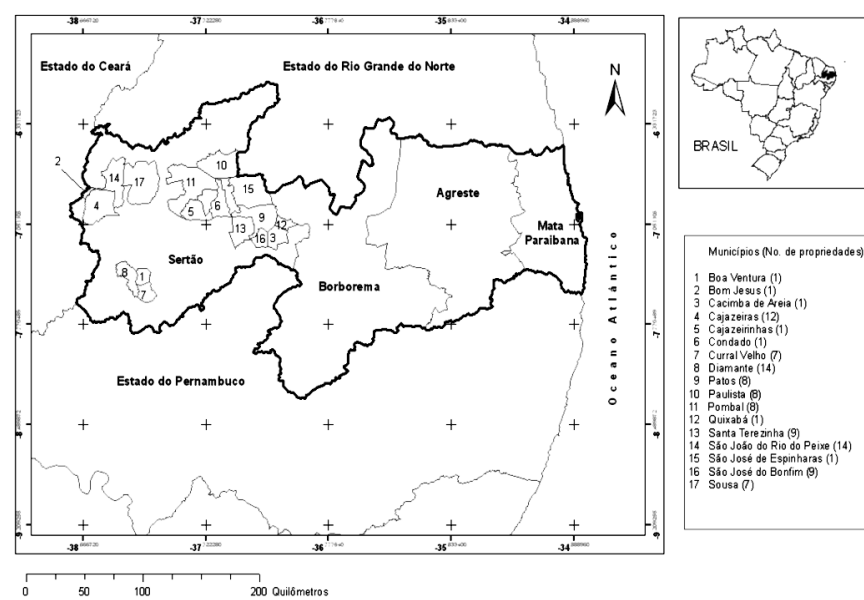

Fig. 1. Estado da Paraíba demonstrando os municípios e respectivos números de propriedades rurais utilizadas, na mesorregião do Sertão paraibano.

Para a análise de fatores de risco associados com a condição de propriedade positiva para a infecção por Brucella ovis foram utilizados os dados colhidos nos questionários epidemiológicos. Uma propriedade foi considerada positiva quando apresentou pelo menos um animal soropositivo. A análise de fatores de risco foi conduzida em duas etapas: análise univariada e análise multivariada. Na análise univariada, cada variável independente foi cruzada com a variável dependente, e aquelas que apresentaram valor de $\mathrm{p} \leq 0,20$ pelo teste de qui-quadrado (Zar 1999) foram selecionadas para a análise multivariada, utilizando-se a regressão logística múltipla (Hosmer \& Lemeshow 2000). O nível de significância adotado na análise múltipla foi de $5 \%$. Todas as análises foram realizadas com o programa SPSS 20.0 for Windows.

\section{RESULTADOS E DISCUSSÃO}

De acordo com os dados obtidos no presente trabalho, 20,39\% (21/103) das propriedades investigadas (Quadro 1) apresentaram pelo menos um ovino soropositivo para Brucella ovis no teste de IDGA. Clementino et al. (2007), no Estado da Paraíba, obtiveram 8,59\% de propriedades com pelo menos um reprodutor ovino soropositivo para B. ovis, no entanto, vale ressaltar que nesse trabalho foram empregados somente carneiros, diferente do presente estudo, no qual foram utilizadas fêmeas em idade de reprodução e reprodutores. Em relação a outros estudos conduzidos em diferentes estados da federação, destaca-se o trabalho de Ramos et al. (1966) que encontraram 18,3\% das propriedades com animais positivos no Rio Grande do Sul, entretanto a técnica utilizada foi apenas avaliação clínica dos reprodutores, procedimento sujeito a grandes falhas, pois somente $50 \%$ dos reprodutores infectados por B. ovis apresentam epididimite clínica (Baigún et al. 2000). No Estado de Alagoas, Pinheiro Junior et al. (2009) verificaram intervalo de frequência nas propriedades que apresentaram sorologia positiva para infecção por B. ovis variando de $3,2 \%$ a 11,8\%, bem como Souza et al. (2011), no Estado da Bahia relataram percentual de 8,62\% (5/58) das propriedades com animais soropositivos, valores inferiores ao verificado neste trabalho, o que pode ser justificado pelo delineamento amostral, que nos dois primeiros trabalhos foi a amostragem por conveniência.
Quadro 1. Prevalência de propriedades positivas (focos) e de animais soropositivos para a infecção por Brucella ovis em ovinos deslanados do semiárido nordestino segundo o município, no período de julho de 2010 a julho de 2011

\begin{tabular}{|c|c|c|c|c|}
\hline \multirow[t]{2}{*}{ Município } & \multicolumn{2}{|c|}{$\begin{array}{l}\text { Prevalência por } \\
\text { propriedades }\end{array}$} & \multicolumn{2}{|c|}{$\begin{array}{l}\text { Prevalência } \\
\text { por animais }\end{array}$} \\
\hline & $\begin{array}{c}\text { No. total } \\
\text { de propri- } \\
\text { edades }\end{array}$ & $\begin{array}{c}\text { No. de pro- } \\
\text { priedades } \\
\text { positivas (\%) }\end{array}$ & $\begin{array}{c}\text { No. total } \\
\text { de animais }\end{array}$ & $\begin{array}{c}\text { No. de ani- } \\
\text { mais soro- } \\
\text { positivos (\%) }\end{array}$ \\
\hline Boa Ventura & 1 & $1(100)$ & 11 & $3(27,3)$ \\
\hline Bom Jesus & 1 & $0(0)$ & 11 & $0(0)$ \\
\hline Cacimba de Areia & 1 & $0(0)$ & 11 & $0(0)$ \\
\hline Cajazeiras & 12 & $1(8,3)$ & 132 & $2(1,5)$ \\
\hline Cajazeirinhas & 1 & $0(0)$ & 13 & $0(0)$ \\
\hline Condado & 1 & $0(0)$ & 11 & $0(0)$ \\
\hline Curral Velho & 7 & $1(14,3)$ & 88 & $0(0)$ \\
\hline Diamante & 14 & $5(35,7)$ & 143 & $12(8,4)$ \\
\hline Patos & 8 & $1(12,5)$ & 101 & $2(2,0)$ \\
\hline Paulista & 8 & $4(50)$ & 88 & $21(23,9)$ \\
\hline Pombal & 8 & $0(0)$ & 88 & $0(0)$ \\
\hline Quixaba & 1 & $1(100)$ & 11 & $2(18,2)$ \\
\hline Santa Terezinha & 9 & $0(0)$ & 110 & $0(0)$ \\
\hline $\begin{array}{l}\text { São João do Rio do } \\
\text { Peixe }\end{array}$ & 14 & $4(28,6)$ & 132 & $9(6,8)$ \\
\hline $\begin{array}{l}\text { São José de Espi- } \\
\text { nharas }\end{array}$ & 1 & $1(100)$ & 10 & $2(20)$ \\
\hline São José do Bonfim & 9 & $0(0)$ & 99 & $3(3,0)$ \\
\hline Sousa & 7 & $2(28,6)$ & 75 & $3(4,0)$ \\
\hline TOTAL & 103 & $21(20,39)$ & 1.134 & $59(5,20)$ \\
\hline
\end{tabular}

Observou-se que 5,20\% (59/1.134) dos animais examinados (Quadro 1) foram soropositivos na IDGA. Na região Nordeste do Brasil destacam-se os trabalhos conduzidos por Clementino et al. (2007), que encontraram prevalência de 5,67\% (28/498) de animais soropositivos em levantamento soroepidemiológico da brucelose por B. ovis em reprodutores ovinos deslanados do semiárido da Paraíba e Pinheiro Junior et al. (2009), que investigando 579 amostras oriundas de 16 rebanhos distribuídos em 23 municípios do Estado de Alagoas utilizando a técnica de IDGA obtiveram prevalência de 3,1\% de animais soropositivos distribuídos em dez propriedades $(43,5 \%)$. Os valores percentuais observados para as diferentes prevalências, mesmo considerando as diferentes regiões, condições de manejo, fatores espaciais e temporais, bem como pelo tipo de amostragem ficaram relativamente próximas, porém inferior ao observado por Azevedo et al. (2004), que encontraram prevalência de $11,3 \%$ para a ocorrência de anticorpos anti-B. ovis em ovinos procedentes de quatro municípios do Estado do Rio Grande do Norte e Coleto et al. (2003), que verificaram $16,25 \%$ de animais soropositivos no Estado de Pernambuco. Souza et al. (2011) no Estado da Bahia, examinando 694 amostras de soros de ovinos, encontraram prevalência de $0,72 \%$ (5/694), bem inferior aos dados encontrados nesta pesquisa. Esses resultados demonstram a disseminação e a importância da enfermidade nos rebanhos ovinos no Nordeste do Brasil e a necessidade de melhor aprofundamento nas praticas sanitárias.

No Quadro 2, com relação à análise de fatores de risco, as variáveis selecionadas para a análise múltipla $(\mathrm{p} \leq 0,20)$ foram aquisição de animais $(p=0,139)$, participar de fei- 
Quadro 2. Análise univariada dos possíveis fatores de risco associados á infecção por Brucella ovis em ovinos deslanados do semiárido nordestino, no período de julho de 2010 a julho de 2011

\begin{tabular}{cccc}
\hline Variáveis & $\begin{array}{c}\text { No. total de } \\
\text { propriedades }\end{array}$ & $\begin{array}{c}\text { No. de proprieda- } \\
\text { des positivas (\%) }\end{array}$ & $\begin{array}{c}\text { Valor } \\
\text { de } \mathrm{p}\end{array}$ \\
\hline
\end{tabular}

\begin{tabular}{l}
\hline Tipo de Exploração \\
Intensiva \\
Semi-intensiva \\
Extensiva \\
Tipo de Criação \\
Cria \\
Recria/engorda \\
Reprodução \\
Subsistência \\
Finalidade da exploração \\
Corte \\
Mista \\
Tamanho do rebanho \\
Até 19 animais \\
20 ou mais animais \\
Criação do tipo tecnificada \\
Não \\
Sim \\
Principal atividade da propriedade \\
Não \\
Sim \\
Contatos com outros animais \\
Não \\
Sim \\
Pastagem nativa \\
Não
\end{tabular}

Sim

Suplementação

Não

Sim

Aquisição de animais

Não

Sim

Participar de feiras e/ou exposições

Não

Sim

Práticas vacinais

Não

Sim

Vermifuga os animais

Não

Sim

Presença de abortos

Não

Sim

Nascimento de crias mortas

Não

Sim

Morte de cordeiros nas primeiras 24 horas

Não

Sim

Morte ao desmame

Não

Sim

Comportamento homossexual

Não

Sim

Presença de plantas toxicas

Não

Sim

$\begin{array}{lr}1 & 0(0) \\ 26 & 4(15,4)\end{array}$

$71 \quad 17(23,9)$

$30 \quad 4(13,3)$

$43 \quad 11(25,6)$

$2(22,2)$

$4(25,0)$

$21(21,6)$

$0(0)$

0,576

$12(23,1)$

$11(21,6)$

$17(21,0)$

$4(26,7)$

$16(20,3)$

$5(27,8)$

$12(27,3)$

$9(17,3)$

0 (0)

21 (21.9)

$12(27,3)$

$7(15,2)$

$5(12,8)$

$16(27,6)$

$17(19,3)$

$2(50,0)$

$15(21,1)$

$6(23,1)$

$2(18,2)$

$19(21,8)$

$11(18,3)$

$9(28,1)$

$13(19,1)$

$7(28,0)$

$16(22,9)$

$4(17,4)$

$16(20,5)$

$4(26,7)$

$7(16,7)$

$1428,0)$

$10(31,3)$

$11(17,7)$

$6(17,1)$

$7(17,1)$

$850,0)$

0,017 *

$7(18,4)$

$9(27,3)$

0,545

0,630

1,000

1,000

0,734

0,530

0,353

1,000

0,253

$0,139 *$

$0,188^{*}$

1,000

1,000

0,413

0,522

0,772

0,732

0,298

0,219

Diariamente

Anualmente

Nascimentos no último ano

Acima de 10 nascimentos

33

ras e/ou exposições $(p=0,188)$ e higiene das instalações $(\mathrm{p}=0,017)$. Na análise múltipla as variáveis apontadas como fatores de risco foram a aquisição de animais (odds ratio $=6,06$; IC 95\% = 1,39-26,48) e a realização de higiene das instalações anualmente (odds ratio $=7,13$; IC 95\%= 1,56-32,47), apresentadas no Quadro 3.

Quadro 3. Fatores de risco associados á infecção por Brucella em ovinos deslanados do semiárido nordestino segundo o município, no período de julho de 2010 a julho de 2011, estimados por regressão logística múltipla

* Variáveis selecionadas para a análise múltipla $(p \leq 0,20)$.

\begin{tabular}{lccc}
\multicolumn{1}{c}{ Fatores de risco } & Odds ratio & IC 95\% & Valor de p \\
\hline Aquisição de animais & 6,06 & $1,39-26,48$ & 0,017 \\
Realizar higiene das instalações & 7,13 & $1,56-32,47$ & 0,011
\end{tabular}

anualmente

Uma condição, relacionada ao manejo dos animais nas propriedades que pode contribuir para a diminuição da ocorrência de doenças infecciosas e parasitárias é a higienização das instalações, uma vez que esta é uma medida básica recomendada para auxiliar no controle de uma série de doenças. No presente trabalho, verificou-se que propriedades que realizavam higiene nas instalações com periodicidade anual apresentaram $50 \%$ de positividade, com odds ratio de 7,13 . Por outro lado, a frequência de positividade em propriedades que realizavam higiene diária e/ou mensal foi de 17,1\%. A higienização e a limpeza das instalações são importantes na prevenção da disseminação da doença devido ao fato das ovelhas infectadas eliminarem B. ovis nas secreções vaginais, placenta e feto abortado (Libal \& Kirkbride 1983, Homse et al. 1995, Estein 1999, Grilló et al. 1999), e como as mucosas oral e nasal e a pele ferida são portas de entrada do agente (Plant et al. 1986, Alton et al. 1988, Bulgin et al. 1990), esses materiais, permanecendo nas instalações, podem contribuir para a disseminação da infecção nos rebanhos (Clementino et al. 2007).

Para a brucelose bovina por Brucella abortus a compra de animais é considerada como o principal fator de risco para a introdução da infecção em rebanhos livres (Crawford et al. 1990), e a intensidade do risco pode variar de acordo com a fonte da compra. No presente trabalho, observou-se que a aquisição de animais também foi fator de risco para a brucelose ovina, e que propriedades que realizam tal prática apresentaram $27,6 \%$ de positividade contra $12,8 \%$ para aquelas que não realizam a compra, com odds ratio de 6,06. Isso reforça ainda mais a necessidade de controle do trânsito de animais destinados à reprodução, principalmente nos casos de participação em eventos que envolvam a aglomeração de animais, como exposições, feiras e leilões, bem como a aquisição apenas de animais soronegativos para a brucelose.

\section{CONCLUSÃO}

Conclui-se que a infecção por Brucella ovis, detectada por sorologia, encontra-se disseminada em propriedades criadoras de ovinos na mesorregião do Sertão do Estado da Paraíba, e baseando-se na análise de fatores de risco, recomenda-se a realização de diagnóstico da infecção previamente à aquisição de animais e realização periódica de higienização das instalações. 
Agradecimentos.- Ao Conselho Nacional de Desenvolvimento Científico e Tecnológico (CNPq) pela concessão de bolsa de Mestrado a F.A. Santos.

\section{REFERÊNCIAS}

Alton G.G., Jones L.M., Angus R.D. \& Verger J.M. 1988. Techniques for the Brucellosis Laboratory. INRA, Paris. 109p.

Azevedo S.S., Alves C.J., Alves F.A.L., Clementino I.J., Batista C.S.A. \& Azevedo A.S. 2004. Ocorrência de anticorpos anti-Brucella ovis em ovinos procedentes de quatro municípios do Estado do Rio Grande do Norte, Brasil. Agropec. Téc., Areia/PB, 25:45-50.

Azevedo S.S., Alves C.J., Andrade J.S.L. \& Santos F.A. 1999. Prevalência de ovinos reagentes à prova de imunodifusão em gel para Brucella ovis na microrregião do Seridó do Rio Grande do Norte. Anais do 4oㅡ Congresso Pernambucano de Medicina Veterinária, Recife, PE, p.269-270.

Baigún R., Conigliaro A.S. \& Luna F. 2000. Aislamiento de Brucella ovis y control de reaccionantes serológicos en epididimitis ovina. Vet. Argentina 17:103-107.

Boblel H., Fernandes J.C.T., Mies Filho A., Ramos A.A. \& Trein E.J. 1972. Estudos sobre a etiologia da epididimite ovina no Rio Grande do Sul. Pesq. Agropec. Bras. 7:1-4.

Brasil 2004. Ministério da Agricultura, Pecuária e Abastecimento, Portaria no 102 de Plano Nacional de Vigilância e Controle da Epididimite Ovina (Brucella ovis), publicada no Diário Oficial da União de 17/12/2004, Seção 1, p.24.

Buddle M.B. \& Boyes B.W. 1953. A Brucella mutant causing genital disease of sheep in New Zealand. Aust. Vet. J. 29:145-153.

Bulgin M.S. 1990. Brucella ovis epizootic in virgin ram lambs. J. Am. Vet. Med. Assoc. 196:1120-1122.

Clementino I.J., Alves C.J., Azevedo S.S., Paulin L.M. \& Medeiros K.A. 2007. Inquérito soro-epidemiológico e fatores de risco associados à infecção por Brucella ovis em carneiros deslanados do semi-árido da Paraíba. Pesq. Vet. Bras. 27:137-143.

Coleto Z.F., Pinheiro Júnior J.W., Mota R.A., Guerra M.M.P., Simplício K.M.M.G., Câmara D.R., Soares R.P.T., Porto W.J.N., Cintra Júnior J., Faustino M.A.G., Souza A.F. \& Berto R.S. 2003. Ocorrência de infecção por Brucella ovis em ovinos do Estado de Pernambuco e sua participação em distúrbios reprodutivos nesta espécie. Revta Bras. Reprod. Anim. 27:551-553.

Crawford R.P., Huber J.D. \& Adams B.S. 1990. Epidemiology and surveillance, p.131-151. In: Nielsen K. \& Duncan J.R. (Eds), Animal Brucellosis. CRC Press, Boca Raton.

Dean A.G. 1994. Epiinfo version 6: a word-processing, database, and statistic program for public health on IBM-compatible microcomputers. Center for Diseases Control and Prevention, Atlanta. 601p.

Fernandes C.E. 2009. Papel do ovino na cadeia epidemiológica da leptospirose pela Leptospira spp. sorovar Hardjo: fatores de risco que envolvem a infecção e transmissão entre ovinos e bovinos. Dissertação de Mestrado em Sanidade Animal, Segurança Alimentar e o Ambiente, Instituto Biológico, São Paulo, SP. 101p.

Estein S.M. 1999. Aspectos inmunológicos em el diagnóstico y control de la epididemitis contagiosa del carnero por Brucella ovis. Arch. Med. Vet. 31:5-17.

Grilló M.J., Marín C.M., Barberán M. \& Blasco J.M. 1999. Experimental Brucella ovis infection in pregnant ewes. Vet. Rec. 144:555-558.

Hilbink F., Wright M. \& Ross G. 1993. Use of the double immuno gel diffusion test and the enzyme-linked immunosorbent assay to distinguish false from true reactors in the complement fixation test for Brucella ovis. N. Z. Vet. J. 41:111-115.
Homse A.C., Casaro A.P. \& Campero C.M. 1995. Infertilidad em ovejas por B. ovis. Vet. Argentina 12:243-249.

Hosmer D.W. \& Lemeshow S. 2000. Applied Logistic Regression. John Wiley and Sons, New York. 375p.

IBGE 2006. Censo Agropecuário de 2006, Instituto Brasileiro de Geografia e Estatística. Disponível em <http://www.ibge.com.br/estadosat/temas.php?sigla $=$ pb\&tema $=$ censoagro $>$ Acessado 28 set. 2012.

Kumar P., Singh D.K. \& Barbeddhe S.B. 1997. Serological evidence of brucellosis in sheep and goats. Indian J. Anim. Sci. 67:180-182.

Libal M.C. \& Kirkbride C.A. 1983. Brucella ovis-induced abortion in ewes. J. Am. Vet. Med. Assoc. 183(5):553-554.

Marinho M. \& Mathias L.A. 1996. Pesquisa de anticorpos contra Brucella ovis em ovinos do estado de São Paulo. Pesq. Vet. Bras. 16:45-48.

Medeiros K.A. 2003. Pesquisa de anticorpos anti-Brucella ovis em reprodutores ovinos deslanados do semi-árido nordestino nos municípios de Patos e São Mamede-PB. Monografia de Especialização em Saúde Pública Veterinária, Universidade Federal de Campina Grande, Patos, PB. 17p.

Niilo L., MacDonald D.W., Godkin G.F. \& Stone M.W. 1986. Ovine brucellosis in Alberta. Can. Vet. J. 27:245-249.

Nozaki C.N., Megid J., Lima K.C., Silva Júnior F.F. \& Veloso C.S. 2004. Comparação das técnicas de imunodifusão em gel de ágar e ELISA no diagnóstico de brucelose ovina em cabanhas da região centro-oeste do estado de São Paulo. Arqs Inst. Biológico, São Paulo, 71:1-5.

Pinheiro Junior J.W., Oliveira A.A.F., Mota R.A., Agottani J.V., Jesus E.M., Assis S.T. \& Oliveira C.Z. 2009. Ocorrência de ovinos sororeatores para Brucella ovis no Estado de Alagoas, Brasil. Vet. Zootec., Botucatu, 16:500508.

Plant J.W., Eamens G.J. \& Seaman J.T. 1986. Serological, bacteriological and pathological changes in rams following different routes of exposure to Brucella ovis. Aust. Vet. J. 63:409-412.

Ramos A.A., Mies Filho A., Schenck J.A.P., Vasconcellos L.D., Prado O.T.G., Fernandes J.C.T. \& Blobel H. 1966. Epididimite ovina. Levantamento clínico no Rio Grande do Sul. Pesq. Agropec. Bras. 1:211-213.

Schäfer I., Vaz A., Ramella J. \& Coutinho G. 1997. Prevalência de carneiros reagentes à prova de imunodifusão em gel para Brucella ovis no Município de Lages-SC. Hora Vet. 17:60-61.

Silva J.B.A., Feijó F.M.C., Teixeira M.F.S. \& Silva J.S. 2003. Prevalência de brucelose ovina causada por Brucella ovis em rebanhos do estado do Rio Grande do Norte, Brasil. Ciênc. Anim. 13:51-54.

Simmons G.C. \& Hall W.T.K. 1953. Epididymitis of rams. Aust. Vet. J. 29:3340.

Souza T.S., Costa J.N., Martinez P.M., Lima C.C.V., Araújo B.R., Neto A.O.C, Anunciação A.V.M., Almeida M.G.A.R. \& Pinheiro R.R. 2011. Inquérito soro-epidemiológico de Brucella ovis em rebanhos ovinos no semiárido baiano. Vet. Zootec., Botucatu,18:697.

Thrusfield M. 1995. Veterinary Epidemiology. $2^{\text {nd }}$ ed. Blackwell Science, Cambridge. 479p.

West D.M., Stafford K.J., Alley M.R., Badcoe L.M., Hilbink E. \& Compton C.W.R. 1993. Serological and necropsy findings for rams infected with Brucella ovis which were not identified by the complement fixation test. N. Z. Vet. J. 41:82-86.

Worthington R.W., Weddell W. \& Penrose M.E. 1984. A comparison of three serological tests for the diagnosis of Brucella ovis infection in rams. N. Z. Vet. J. 32:58-60.

Zar J.H. 1999. Biostatistical analysis. $4^{\text {th }}$ ed. Prentice-Hall, New Jersey. $663 p$. 